\title{
Variability in gene cassette patterns of class 1 and 2 integrons associated with multi drug resistance patterns in Staphylococcus aureus clinical isolates in Tehran-Iran
}

Mahdi Mostafa ${ }^{1,2}$, Seyed Davar Siadat ${ }^{1 *}$, Fereshteh Shahcheraghi ${ }^{3}$, Farzam Vaziri ${ }^{1}$, Alireza Japoni-Nejad ${ }^{1}$, Jalil Vand Yousefi ${ }^{2}$, Bahareh Rajaei ${ }^{4}$, Elnaz Harifi Mood', Nayyereh Ebrahim zadeh', Arfa Moshiri ${ }^{5}$,

Seyed Alireza Seyed Siamdoust ${ }^{6}$ and Mohamad Rahbar ${ }^{7}$

\begin{abstract}
Background: To investigate antibiotic resistance, the occurrence and distribution of class 1 and 2 integrons in multidrug- resistant Staphylococcus aureus isolates from hospitals in Tehran, Iran.

The isolates were examined for susceptibility to antimicrobial agents. The mecA gene, class 1 and 2 integrons were detected by PCR. Integrase positive strains were further analysed for the presence of resistance gene cassettes using specific primers and were sequenced.

Results: Among 139 S.aureus isolates, 109 (78.4\%) and 112 (80.5 \%) strains were considered as multidrug resistant and mecA positive, respectively. Class 1 integrons and internal variable regions were found in $72.6 \%(101 / 139)$ and $97 \%(98 / 101)$ and class 2 integrons and variable regions also in $35.2 \%$ (49/139) and $65.3 \%$ (32/49) of S.aureus clinical isolates, respectively. Twelve distinct cassette arrays were found, containing genes encoding resistance to $\beta$-lactams, aminoglycosides, streptothricin, trimethoprim, chloramphenicol,a putative glucose dehydrogenase precursor and a protein with unknown function. Gene cassette arrays aadB, aadA2 and dhfrA1-sat2-aadA1 were common in S.aureus isolates. We detected a completely new gene cassettes which contained aadB, oxa2, aacA4, orfD-aacA4-catB8, aadB-catB3, orfD-aacA4 and aadB-aadA1-cmlA6 of class 1 and dhfrA1-sat2-aadA1, dhfrA11, dhfrA1-sat2 of class 2 integrons.
\end{abstract}

Conclusions: This is the first study to report carriage of class 1 and 2 integrons and associated gene cassettes among in S.aureus isolates from Iran.

Keywords: Staphylococcus aureus, Gene cassettes, Integrons, Multidrug-resistant, Iran

\section{Background}

Staphylococcus aureus has long been recognized as a major human pathogen responsible for a wide range of infections, from mild skin infections to wound infections and bacteraemia [1]. Although the introduction of antibiotics has lowered the mortality rate from $S$. aureus infections, the bacteria have developed resistance mechanisms to all antimicrobial agents that have been produced [1].

\footnotetext{
* Correspondence: d.siadat@gmail.com

'Department of Mycobacteriology \& Pulmonary Research, Pasteur Institute of Iran, Tehran-Iran, No. 358, 12th Farwardin Ave, Jomhhoori St, Tehran 1316943551, Iran

Full list of author information is available at the end of the article
}

Despite antibiotic therapy, staphylococcal infections occur regularly in hospitalized patients and have severe consequencess $[2,3]$. Due to an increasing number of infections caused by methicillin-resistant $S$. aureus (MRSA) strains, which are now most often multiresistant, therapy has become problematic [4]. Since this organism can spread easily by direct or indirect contact between patients and the environment, or among patients and medical personnel, $S$. aureus is an important cause of nosocomial infection, and major outbreaks are common $[5,6]$.
C Biomed Central

(c) 2015 Mostafa et al. This is an Open Access article distributed under the terms of the Creative Commons Attribution License (http://creativecommons.org/licenses/by/4.0), which permits unrestricted use, distribution, and reproduction in any medium, provided the original work is properly credited. The Creative Commons Public Domain Dedication waiver (http:// creativecommons.org/publicdomain/zero/1.0/) applies to the data made available in this article, unless otherwise stated. 
Dissemination of antibiotic resistance genes by horizontal gene transfer has led to the rapid emergence of antibiotic resistance among bacteria, thus complicating the treatment of infections [7]. Acquired resistance evolves via horizontal transfer of antimicrobial resistance genes located on various types of mobile DNA elements. A key system involved in spreading antibiotic multiresistance is the integron, an element that, although normally immobile itself, can be transferred through mobile genetic elements $[8,9]$. Integrons are genetic elements that incorporate exogenous open reading frames by recombination and convert them to functional genes [10]. All integrons characterized to date are composed of these major elements: a gene (intI) encoding an integrase; a primary recombination site (attI); and an outward orientated promoter $(\mathrm{Pc})$ that directs transcription of the captured genes [11].

In this study, the presence of integrons and gene cassettes in S. aureus has been studied for the first time in Iran.

The objective of this research was to identified multiple drug resistance in clinical isolates of $s$. aureus by antibiotic sensitivity testing, detection of $m e c A$ gene for methicillin-resistant $S$. aureus strains, and distribution of class 1 and 2 integrons and associated gene cassettes among S.aureus isolates collected from clinical sources in Tehran by PCR assays and investigates associations between multidrug resistance and the existence of integrons.

\section{Methods}

\section{Sampling and bacterial isolation}

One hundred and thirty nine $S$. aureus isolates were collected from hospitals in Tehran, over a six month period, starting from the first of October 2011 till the end of March 2012 . The isolates were recovered from wounds $(n=31)$, blood $(n=31)$, urines $(n=28)$, nasal swabs $(n=21)$, catheters $(n=5)$, sternum samples $(n=5)$, sputa $(n=4)$, eyes $(n=2)$, CSF $(n=1)$, synovial fluid $(n=1)$, throat samples $(n=3)$ and abscesses $(n=7)$. The isolates were identified as $S$. aureus by standard biochemical tests for catalase, coagulase, clumping factor, DNase, and thermostable nuclease. All isolates were also evaluated for the presence of the sa442 gene by PCR [3, 12]. The research was approved by the Ethics committee of the Pasteur Institute of Iran (no = 402) and acquire either verbal or written informed consent from the patients to take their samples for this study.

\section{Antibiotic susceptibility test}

The isolated S. aureus strains were tested for their in vitro antimicrobial susceptibility using the disk diffusion technique on Mueller- Hinton agar (Mast, UK). The results were recorded after $18 \mathrm{~h}$ of incubation at $37 € \mathrm{C}$.
Antimicrobial drugs tested included Penicillin G; PG(30 $\mu \mathrm{g})$, Amoxicillin; A(25 $\mu \mathrm{g})$, Linezolid; LZD(30 $\mu \mathrm{g})$, Streptomycine; $\mathrm{S}(10 \mu \mathrm{g})$, Ampicillin; $\operatorname{AP}(10 \mu \mathrm{g})$, Tetracycline; $\mathrm{T}(30 \mu \mathrm{g})$, Chloramphenicol; C $(30 \mu \mathrm{g})$, Sulfamethoxazole-Trimethoprim; SXT $(30 \mu \mathrm{g})$, Amikacin; AK(30 $\mu \mathrm{g})$, Azithromycin; ATH(15 $\mu \mathrm{g})$, Spectinomycin; SPC(100 $\mu \mathrm{g})$, Gentamicin; GM(10 $\mu \mathrm{g})$, Vancomycin; VA(30 $\mu \mathrm{g})$, Teicoplanin; TEC(30 $\mu \mathrm{g})$, Ciprofloxacin; CIP(5 $\mu \mathrm{g})$, Oxacillin; OX $(1 \mu \mathrm{g})$, Levofloxacin; LEV(5 $\mu \mathrm{g})$, Gatifloxacin; GAT(5 $\mu \mathrm{g})$, Rifampin; RP(5 $\mu \mathrm{g})$, Erythromycin; $\mathrm{E}(15 \mu \mathrm{g})$, Ceftriaxone; $\mathrm{CRO}(30 \mu \mathrm{g})$, Tobramycin; $\mathrm{TN}(10 \mu \mathrm{g})$, Clindamycin; $\mathrm{CD}(2 \mu \mathrm{g})$. The MIC to vancomycin was determined by Etest (bioMerrieux). Enterococcus faecalis ATCC 29212 and Enterococcus faecium BM4147 were used as controls for vancomycin susceptibility and vancomycin resistance, respectively. The breakpoints for antibiotic susceptibility were determined according to the guidelines of the Clinical and Laboratory Standards Institute (CLSI) [13]. E. coli ATCC 25922 was used as a reference control strain. Isolates of S.aureus that show resistance to three or more than three classes of antibiotics, considered as multidrug - resistant strains.

\section{The extraction of S. aureus plasmid and genomic DNA}

The genomic DNA preparation used in this study was performed following Sambrook et al. [14]. The DNA was extracted with phenol-chloroform and precipitated by ice-cold ethanol. The DNA pellet was washed with $70 \%$ ethanol and resuspended in $50 \mu \mathrm{l}$ of TE buffer $(10 \mathrm{mM}$ Tris; $1 \mathrm{mM}$ EDTA, pH8) and stored at $-20 € \mathrm{C}$ until used and $1 \mu \mathrm{l}$ of the suspension were used as the template DNA for PCR. Using the primers determined [3] mecA gene was detected by PCR. Size of the amplified fragment was $533 \mathrm{bp}$.

The Qiagen Plasmid Midi Kit was used for the S. aureus plasmid DNA extraction; the manufacturer's instructions were followed.

\section{Detection of class 1 and 2 integrons}

All isolates were screened for detection of class 1 and 2 integrons by the primers described by Moura et al. [15] designed for the intI1 and intI2 genes respectively. Primers intI1 F/R and intI2 F/R were used to amplify $280 \mathrm{bp}$ and $232 \mathrm{bp}$ fragments, respectively. The amplification program was performed by termocycler (Eppendorf Mastercycler", MA) and started with initial denaturation of $4 \mathrm{~min}$ at $94{ }^{\circ} \mathrm{C}$ and programmed wi th 35 cycles of each: $1 \mathrm{~min}$ at $94{ }^{\circ} \mathrm{C}$, $30 \mathrm{~s}$ at $55^{\circ} \mathrm{C}, 1 \mathrm{~min}$ at $72{ }^{\circ} \mathrm{C}$. The program finished with the final extension of $10 \mathrm{~min}$ at $72{ }^{\circ} \mathrm{C}$.

\section{Mapping of class 1 and 2 integrons}

The gene cassettes inserted in the variable regions of class 1 and 2 integrons (IVR) were amplified using the primer pairs introduced by Moura et al. [15]. 


\section{Sequencing of amplified integron gene cassettes}

For each PCR product that had a unique size when visualized on the gel, a number of samples of the postPCR mixture was processed with the High Pure PCR Product Purification kit (Roche,USA) and used for direct sequencing. The purified amplicons were sequenced using the ABI Capillary System (Pasteur Institute, Tehran, Iran). Resulting sequences were assembled by using SeqMan program within the Lasergene suite version 7 (DNAstar Inc, Madison, WI, USA). Potential open reading frames (ORFs) were predicted by using the NCBI (National Center for Biotechnology Information) ORF Finder tool (http://www.ncbi.nlm.nih.gov/ gorf/gorf.html). BLAST (http://blast.ncbi.nlm.nih.gov/ Blast.cgi) against GenBank database and The Integron Database INTEGRALL (http://integrall.bio.ua.pt/) were performed repeatedly for sequence comparison and annotation.

\section{Statistical analysis}

The antibiotic resistance data between integron-positive isolates and integron-negative isolates was compared and the $x^{2}$ test was used to calculate the $P$ value in terms of resistant and susceptible numbers by SPSS version 18 software. A $P$ value of $<0.05$ was considered statistically significant.

\section{Results}

A total of 139 S. aureus isolates were collected from clinical specimens of hospitals in Tehran, over a 6 month period, starting from the first of October 2011 till the end of March 2012.

\section{Antibiotic susceptibility test}

The antimicrobial resistance patterns of isolates are shown in Tables 1 and 2. According to the results of the vancomycin Etest, all isolates were susceptible to this agent. Of the 139 isolates, 109 (78.4\%) isolates were designated as MDR S.aureus. Overall, 112 (80.5 \%) isolates were resistant to methicillin and were confirmed as MRSA based on the detection of the mecA gene. Distribution of mecA gene in MRSA isolates from nosocomial sources are shown in Fig. 1. All of the MRSA isolates were susceptible to Vancomycin and Teicoplanin (100 \%). Also all MRSA isolates were resistant to Amoxicillin (100 \%) and Ampicillin (100\%), Tetracycline 69 (61.6\%), Amikacin 40 (35.7\%), Ceftriaxone 68 (60.7\%), Gentamicin 73 (65.1\%), Spectinomycin 77 (68.7\%),

Table 1 Correlation of antibiotic resistance between class 1 integron-positive and integron-negative of S.aureus

\begin{tabular}{|c|c|c|c|c|c|c|c|}
\hline \multirow[t]{2}{*}{ Antibiotics } & \multicolumn{2}{|c|}{ All strains of S.aureus $(n=139)$} & \multicolumn{2}{|c|}{ Integron-positive isolates $(n=101)$} & \multicolumn{2}{|c|}{ Integron-negative isolates $(n=38)$} & \multirow{2}{*}{$\begin{array}{l}P \\
\text { value }\end{array}$} \\
\hline & $\mathrm{R}$ & $\mathrm{S}$ & $\mathrm{R}$ & S & $\mathrm{R}$ & S & \\
\hline$A K^{*}$ & $43(31 \%)$ & $96(69 \%)$ & $35(34.7 \%)$ & $66(25.3 \%)$ & $8(21 \%)$ & $30(79 \%)$ & 0.088 \\
\hline $\mathrm{SXT}^{*}$ & $38(27.3 \%)$ & $101(72.7 \%)$ & $34(33.7 \%)$ & $67(66.3 \%)$ & $4(10.5 \%)$ & $34(89.5 \%)$ & 0.004 \\
\hline $\mathrm{C}^{*}$ & $49(32.3 \%)$ & $90(64.7 \%)$ & $41(40.6 \%)$ & $60(59.4 \%)$ & $8(21 \%)$ & $30(79 \%)$ & 0.024 \\
\hline$T E^{*}$ & $78(56.1 \%)$ & $61(43.9 \%)$ & $65(64.4 \%)$ & $36(35.6 \%)$ & $13(34.2 \%)$ & $25(65.8 \%)$ & 0.001 \\
\hline $\mathrm{CIP}^{*}$ & $56(40.3 \%)$ & $83(59.7 \%)$ & 49 (48.5 \%) & $52(51.5 \%)$ & 7 (18.4 \%) & $31(81.6 \%)$ & 0.001 \\
\hline $\mathrm{GM}^{*}$ & $76(54.7 \%)$ & $63(45.3 \%)$ & $68(67.3 \%)$ & $33(32.7 \%)$ & $8(21 \%)$ & $30(79 \%)$ & $<0.001$ \\
\hline$S P C^{*}$ & $86(61.9 \%)$ & $53(38.1 \%)$ & 73 (72.3 \%) & $28(27.7 \%)$ & 13 (34.2\%) & 25 (65.8\%) & $<0.001$ \\
\hline ATH $^{*}$ & 69 (49.6\%) & 70 (50.4 \%) & 62 (61.4\%) & 39 (38.6\%) & 7 (18.4\%) & 31 (81.6\%) & $<0.001$ \\
\hline$S^{*}$ & 75 (54 \%) & 64 (46 \%) & $61(60.4 \%)$ & 40 (39.6\%) & 14 (37 \%) & 24 (63\%) & 0.011 \\
\hline GAT & 44 (31.7 \%) & 95 (68.3\%) & 32 (31.7 \%) & 69 (68.3\%) & 12 (31.6\%) & $26(68.4 \%)$ & 0.581 \\
\hline OXA & 104 (74.8\%) & 35 (25.2 \%) & 76 (75.2 \%) & 25 (24.8\%) & 28 (73.7 \%) & $10(26.3 \%)$ & 0.505 \\
\hline$P G$ & 137 (98.6 \%) & $2(1.4 \%)$ & $101(100 \%)$ & $0(0 \%)$ & 36 (94.7 \%) & $2(5.3 \%)$ & 0.073 \\
\hline RP & 43 (31\%) & 96 (69 \%) & 31 (30.7 \%) & 70 (69.3\%) & 12 (31.6\%) & $26(68.4)$ & 0.537 \\
\hline LZD & 24 (17.3\%) & $115(82.7 \%)$ & $20(19.8 \%)$ & 81 (80.2 \%) & $4(10.5 \%)$ & 34 (89.5 \%) & 0.149 \\
\hline$C D$ & $84(60.4 \%)$ & $55(39.6 \%)$ & 65 (64.4\%) & 36 (35.6\%) & 19 (50 \%) & 19 (50 \%) & 0.089 \\
\hline$E^{*}$ & 95 (68.3\%) & 44 (31.7 \%) & 78 (77.2 \%) & $23(22.8 \%)$ & 17 (44.7 \%) & $21(55.3 \%)$ & $<0.001$ \\
\hline TN & 66 (47.5\%) & 73 (52.5 \%) & 46 (45.5\%) & $55(54.5 \%)$ & 20 (52.6\%) & 18 (47.4 \%) & 0.289 \\
\hline $\mathrm{LEV}^{*}$ & $56(40.3 \%)$ & 83 (59.7 \%) & $49(48.5 \%)$ & $52(51.5 \%)$ & 7 (18.7\%) & $31(81.6 \%)$ & 0.001 \\
\hline $\mathrm{CRO}^{*}$ & 71 (51.1\%) & 68 (48.9 \%) & 66 (65.3 \%) & 35 (34.7\%) & 5 (13.1\%) & 33 (86.9 \%) & $<0.001$ \\
\hline
\end{tabular}

*: significant values, AK Amikacin, SXT Trimethoprim- Sulfamethoxazole, C Chloramphenicol, TE Tetracycline, CIP Ciprofloxacin, GM Gentamicin, SPC Spectinomycin, ATH Azithromycine, S Streptomycin, GAT Gatifloxacin, OXA Oxacillin, PG Penicillin G, RP Rifampin, LZD Linezolid, CD Clindamycin, E Erythromycin, TN Tobramycin, LEV Levofloxacin, CRO Ceftriaxone; $R$ Resistant, $S$ sensitive 
Table 2 Correlation of antibiotic resistance between class 2 integron-positive and integron-negative of S. aureus

\begin{tabular}{|c|c|c|c|c|c|c|c|}
\hline \multirow[t]{2}{*}{ Antibiotics } & \multicolumn{2}{|c|}{ All strains of S.aureus $(n=139)$} & \multicolumn{2}{|c|}{ Integron-positive isolates $(n=49)$} & \multicolumn{2}{|c|}{ Integron-negative isolates $(n=90)$} & \multirow{2}{*}{$\begin{array}{l}P \\
\text { value }\end{array}$} \\
\hline & R & $\mathrm{S}$ & R & $S$ & $\mathrm{R}$ & $\mathrm{S}$ & \\
\hline$A K^{*}$ & $43(31 \%)$ & $96(69 \%)$ & $21(42.9 \%)$ & $28(57.1 \%)$ & $22(24.4 \%)$ & $68(75.6 \%)$ & 0.021 \\
\hline$S X T^{*}$ & $38(27.3 \%)$ & $101(72.7 \%)$ & $24(49 \%)$ & $25(51 \%)$ & $14(15.5 \%)$ & $76(84.5 \%)$ & $<0.001$ \\
\hline C & $21(42.9 \%)$ & $28(57.1 \%)$ & $21(42.9 \%)$ & 28 (57.1\%) & $28(31.1 \%)$ & $62(68.9 \%)$ & 0.116 \\
\hline $\mathrm{TE}^{*}$ & $78(56.1 \%)$ & 61 (43.9\%) & $38(77.5 \%)$ & $11(22.5 \%)$ & 40 (44.4\%) & $50(55.6 \%)$ & $<0.001$ \\
\hline $\mathrm{CIP}^{*}$ & $56(40.3 \%)$ & $83(59.7 \%)$ & $28(57.1 \%)$ & $21(42.9 \%)$ & $28(31.1 \%)$ & $62(68.9 \%)$ & 0.003 \\
\hline $\mathrm{GM}^{*}$ & $76(54.7 \%)$ & $63(45.3 \%)$ & $37(75.5 \%)$ & $12(24.5 \%)$ & $39(43.3 \%)$ & $51(56.7 \%)$ & $<0.001$ \\
\hline$S P C^{*}$ & $86(61.9 \%)$ & $53(38.1 \%)$ & 41 (83.7 \%) & $8(16.3 \%)$ & 45 (50 \%) & 45 (50 \%) & $<0.001$ \\
\hline ATH $^{*}$ & 69 (49.6\%) & 70 (50.4 \%) & 36 (73.5 \%) & 13 (26.5\%) & 33 (36.7 \%) & $57(63.3 \%)$ & $<0.001$ \\
\hline$S^{*}$ & 75 (54 \%) & 64 (46 \%) & 34 (69.4\%) & 15 (30.6 \%) & 41 (45.6\%) & 49 (54.4\%) & 0.006 \\
\hline GAT & 44 (31.7 \%) & 95 (68.3 \%) & 19 (38.8\%) & $30(61.2 \%)$ & 25 (27.8\%) & 65 (72.2 \%) & 0.127 \\
\hline OXA & 104 (74.8 \%) & 35 (25.2 \%) & 41 (83.7 \%) & 8 (16.3 \%) & 63 (70 \%) & 27 (30 \%) & 0.056 \\
\hline$P G$ & 137 (98.6 \%) & 2 (1.4\%) & 49 (100\%) & $0(0 \%)$ & 88 (97.8 \%) & 2 (2.2\%) & 0.418 \\
\hline RP & 43 (31\%) & 96 (69 \%) & 18 (36.7 \%) & $31(63.3 \%)$ & 25 (27.8\%) & $65(72.2)$ & 0.184 \\
\hline LZD & $24(17.3 \%)$ & $115(82.7 \%)$ & $9(18.4 \%)$ & $40(81.6 \%)$ & 15 (16.7\%) & 75 (83.3 \%) & 0.486 \\
\hline$C D$ & 84 (60.4 \%) & $55(39.6 \%)$ & 34 (69.4\%) & 15 (30.6\%) & $50(55.6 \%)$ & 40 (44.4\%) & 0.078 \\
\hline$E^{*}$ & 95 (68.3 \%) & $44(31.7 \%)$ & 40 (81.6\%) & 9 (18.4\%) & 55 (61.1\%) & 35 (38.9 \%) & 0.01 \\
\hline TN & 66 (47.5 \%) & 73 (52.5 \%) & 26 (53 \%) & 23 (47 \%) & 40 (44.4\%) & $50(55.6 \%)$ & 0.214 \\
\hline LEV* & $56(40.3 \%)$ & 83 (59.7 \%) & 28 (57.1\%) & $21(42.9 \%)$ & 28 (31.1\%) & 62 (68.9\%) & 0.003 \\
\hline $\mathrm{CRO}^{*}$ & 71 (51.1\%) & 68 (48.9 \%) & 38 (77.5 \%) & 11 (22.5 \%) & 33 (36.7 \%) & 57 (63.3\%) & $<0.001$ \\
\hline
\end{tabular}

*: significant values AK, Amikacin, SXT Trimethoprim- Sulfamethoxazole, C Chloramphenicol, TE Tetracycline, CIP Ciprofloxacin, GM Gentamicin, SPC Spectinomycin, ATH Azithromycine, S Streptomycin, GAT Gatifloxacin, OXA Oxacillin, PG Penicillin G, RP Rifampin, LZD Linezolid, CD Clindamycin, E Erythromycin, TN Tobramycin, LEV Levofloxacin, CRO Ceftriaxone, $R$ Resistant, $S$ sensitive

Ciprofloxacin 51 (45.5\%), Chloramphenicol 45 (40.1\%), Oxacillin 93 (83\%), Gatifloxacin 39 (34.8\%), Erythromycin 89 (79.4\%), Azithromycin 67 (59.8\%), Tobramycin 57 (50.8 \%), Levofloxacin 55 (49.1\%), Rifampin 37 (33 \%), Penicillin G 111 (99.1\%), Streptomycin 69 (61.6 \%) and Clindamycin 73 (65.1\%). The least resistance to the following antibiotics are observed: Sulfamethoxazole-Trimethoprim 34 (30.3 \%), and Linezolid 18 (16\%).

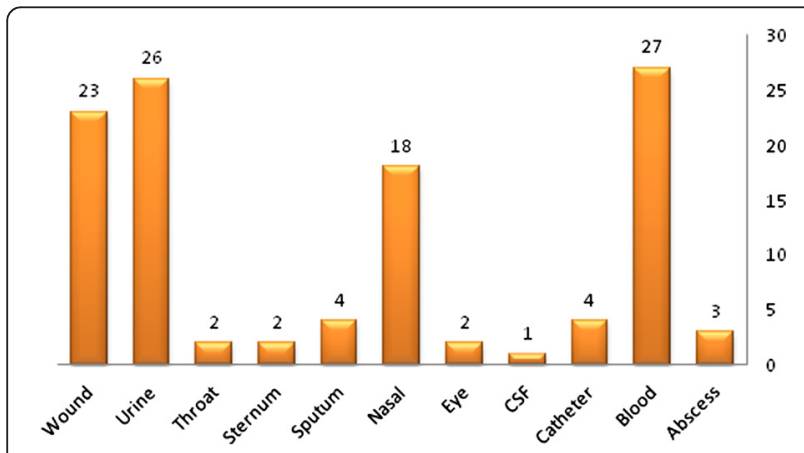

Fig. 1 Distribution of mecA gene in MRSA isolates from nosocomial sources

\section{Detection of class 1 and 2 Integrons}

One hundred and thirty-nine of S.aureus, were examined for the presence of known markers for integrons by PCR amplification. The 101 (72.6\%) isolates were positive for class 1 integron with the amplicon size of $280 \mathrm{bp}$ and class 2 integron was found in 49 (35.2\%) isolates with the amplicon size of $232 \mathrm{bp}$. Information about integron positive isolates among different sources of S.aureus isolates are shown in Table 3. In the present study, among of 112 strains of MRSA, 95 (84.8 \%) isolates carrying class 1 integron as well as 46 (41\%) isolates carrying class 2 integron.

The results indicate that resistance to several different antibiotics is associated with the presence of the integron. Tables 1 and 2 shows the antibiotic susceptibilities of integron-positive and integron-negative isolates to each of the antibiotics. Both class 1 and 2 integrases genes were present together in $44(31.6 \%)$ strains of S.aureus.

Antimicrobial susceptibility testing showed the multidrug resistance rates of integron-positive class 1 and negative strains were $72.6 \%(101 / 139)$ and $27.4 \%$ (38/ 139) and also rates of integron-positive class 2 and negative strains were $35.2 \%(49 / 139)$ and $64.8 \%(90 / 139)$, respectively. 
Table 3 Information about integron positive isolates among different sources of S.aureus isolates

\begin{tabular}{llll}
\hline $\begin{array}{l}\text { Isolation } \\
\text { source(No) }\end{array}$ & $\begin{array}{l}\text { No. of intl1 } \\
\text { positive isolates (\%) }\end{array}$ & $\begin{array}{l}\text { No. of intl2 } \\
\text { positive isolates (\%) }\end{array}$ & $\begin{array}{l}\text { No. of int1 and } \\
\text { int2 positive } \\
\text { isolates (\%) }\end{array}$ \\
\hline $\begin{array}{l}\text { Abscesses } \\
\text { (7) }\end{array}$ & 4 & 3 & 3 \\
Blood (31) & 24 & 11 & 10 \\
Catheter (5) & 3 & 3 & 3 \\
CSF (1) & 1 & 0 & 0 \\
Eye (2) & 2 & 0 & 0 \\
Nasal (21) & 14 & 1 & 1 \\
Sputum (4) & 2 & 3 & 2 \\
Sternum (5) & 2 & 0 & 0 \\
Throat (3) & 2 & 3 & 2 \\
Urine (28) & 25 & 11 & 11 \\
Wound (31) & 22 & 14 & 12 \\
Synovia (1) & 0 & 0 & 0 \\
Total (139) & 101 (72.6\%) & $49(35.2 \%)$ & $44(31.6 \%)$ \\
\hline
\end{tabular}

Of 101 isolates carrying class 1 integrons, 89 (88.1\%) isolates amplified class 1 integrons on chromosome, 12 (11.9\%) isolates on plasmid. Among 49 isolates harbored class 2 integrons, 11 (22.4\%) isolates carried class 2 integrons only on chromosome and 38 (77.6\%) isolates on plasmid.

\section{Characterization of gene cassettes in class 1 and 2 integrons}

Of the 139 s.aureus isolates, 101 (72.6\%) isolates were identified as being positive for class 1 integron. PCR amplification of the integron cassette region occurred in 98 (97\%) class 1 integron containing isolates (Table 4). Class 2 integron was detected in 49 (35.2 \%) isolates.

Table 4 Sizes of variable regions of integron class I cassettes in intl1 positive isolates

\begin{tabular}{ll}
\hline Pattern of integron I cassettes bands (bp) & No. of isolates (\%) \\
\hline 500 & $1(0.99)$ \\
750 & $49(48.5)$ \\
800 & $3(2.9)$ \\
1000 & $36(35.6)$ \\
1100 & $1(0.99)$ \\
1200 & $3(2.9)$ \\
1420 & $2(1.98)$ \\
2120 & $1(0.99)$ \\
3110 & $2(1.98)$ \\
Without PCR product & $3(2.9)$ \\
Total no. of intl1 positive isolates & $101(100)$ \\
\hline
\end{tabular}

The integron cassette region could not be amplified by PCR in 17 (34.6\%) of the class 2 integron-containing isolates (Table 5). Schematic representation of the various cassette arrays found in class 1 and class 2 integrons are shown in Fig. 2.

\section{Nucleotide sequence accession numbers}

The nucleotide sequence data reported in this article are available in the GenBank nucleotide database under GenBank accession numbers KF030468, KF411134, KF305706, KF411137, KF411135, KF411133, KF356395, KF305707, KJ002505, KJ002506,KF015994,KF015995, KF411138,KF411139 obtained from the gene cassette of class 1 integrons and KF305708, KF305710, KF411136, KJ769139 obtained from the gene cassette of class 2 integrons, overall, 18 strains were sequenced (Table 6).

\section{Discussion}

In the current study, prevalence of intI 1 and intI 2 were examined among multidrug resistant S.aureus strains, isolated from different specimens. The prevalence of antimicrobial-resistant bacterial pathogens has become a major public health concern [16, 17]. Horizontal gene transfer has already been proved a significant mechanism for disseminating antimicrobial resistance in bacterial populations. Antimicrobial drug resistance can also be facilitated by integrons in case of many other bacteria [18-21]. Since the integrons were detected first in Gram-negative bacteria, many studies have been conducted on Gram-negative bacteria. Although the role of class 1integrons is well known in the spread of antibiotic resistance genes in gram-negative bacteria, much less is known about gram-positive bacteria and very few studies have reported the presence of class 1 integrons in grampositive bacteria so increasing antibiotic resistance mediated by integrons in gram-positive bacteria has become a great concern in the medical field [22].

Integrons are genetic elements able to recognize and capture mobile gene cassettes carrying antibiotic resistance genes leading to MDR distribution and subsequently limitation of treatment options for infections [23].

To our knowledge, this is the first study to report carriage of class 1 and 2 integrons and associated gene cassettes in S.aureus isolates from Iran. Our findings demonstrate that

Table 5 Sizes of variable regions of integron class 2 cassettes inint12 positive isolates

\begin{tabular}{ll}
\hline Pattern of integronll cassettes bands (bp) & No. of isolates (\%) \\
\hline 750 & $8(16.3)$ \\
1238 & $5(10.2)$ \\
2500 & $19(38.7)$ \\
Without PCR product & $17(34.6)$ \\
Total no. of int12 positive isolates & $49(100)$ \\
\hline
\end{tabular}




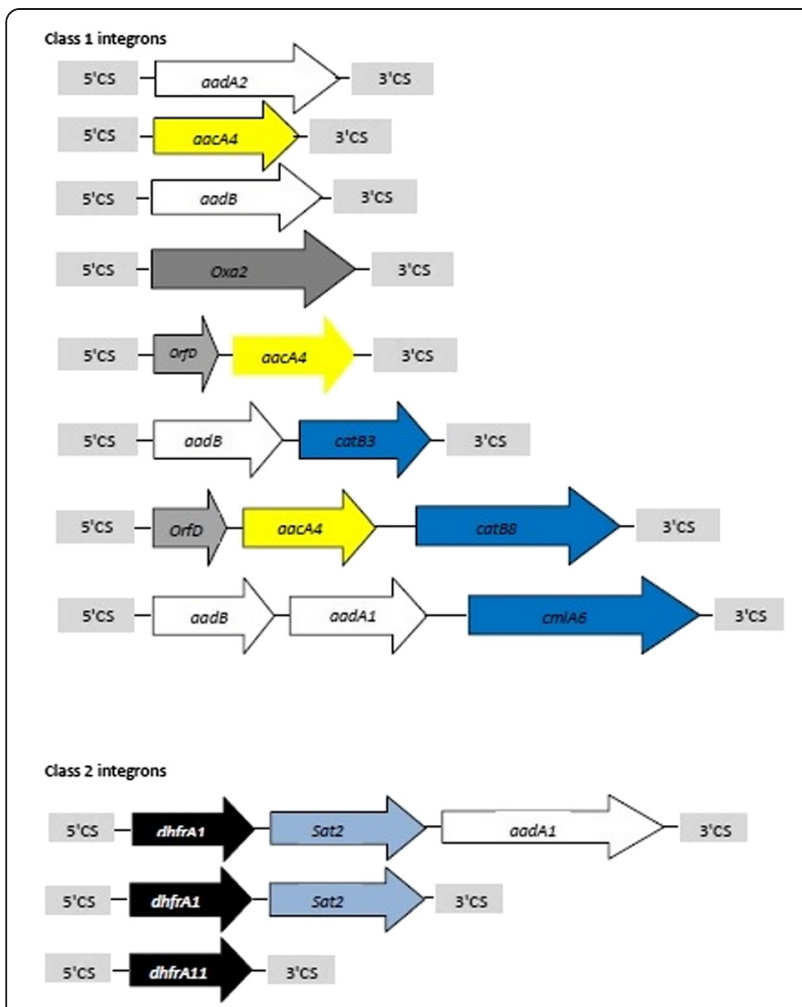

Fig. 2 Schematic representation of the various cassette arrays found in class 1 and class 2 integrons. The arrows display the open reading frames of the different genes. All $\operatorname{aad} A$ and $a a d B$ genes are presented as white arrows, dhfrA, aacA4, orfD, oxa2, catB, cmlA6, sat2 genes are presented as black, yellow, light grey, grey, blue and light blue arrows respectively. The grey light boxes indicate the $3^{\prime}$ and $5^{\prime}$ CSs of class1 or class 2 integrons

integrons are widespread among S.aureus clinical isolates in Tehran. Most resistant pattern was observed in amoxicillin, ampicillin, oxacillin, erythromycin, tetracycline, gentamicin, tobramycin, streptomycine, spectinomycin, ciprofloxacin, azithromycine, penicillin G, clindamycin, levofloxacin, ceftriaxone and antibiotic such as vancomycin, teicoplanin, linezolid and trimethoprim-sulfamethoxazole were considered as the most effective drugs against S.aureus strains that this results largely agrees to findings of $\mathrm{Xu}$ et al. about amoxicillin/clavulanic acid, ciprofloxacin, clindamycin, erythromycin, gentamicin, levofloxacin, oxacillin, tetracycline, trimethoprim-sulfamethoxazole and the result of Ren et al. about oxacillin, erythromycin, azithromycin, clindamycin, amoxicillin/clavulanic acid, ciprofloxacin, tetracycline, gentamycin $[24,25]$.

Among different classes of integrons, class 1 integrons have been found more frequently in different species of bacteria, especially Gram-negative bacteria $[11,26,27]$. The classification of different integrons is mainly based on differences in the gene structure of integrases [11].
In this survey, presence of integrons in strains of S.aureus as compared to similar studies conducted by $\mathrm{Xu}$ et al. and Ren et al. has been increased [24, 25]. The rate of detection of integron class 1 was more than integron class 2 . One hundred and one $(72.6 \%)$ isolates were positive for class 1 integron and $49(35.2 \%)$ isolates were positive for class 2 integron.

The nine different cassettes arrangements wich class 1 integrons and another three arrangements within class 2 integrons were identified.

Twelve different gene cassettes were detected. Cassette genes encoding resistance to aminoglycosides were found to be predominant in the class 1 integron. The $a a d B$ and $\operatorname{aad} A$ types genes that encode resistance to aminoglycosides (aadB gene cassette conferring resistance to gentamicin, tobramycin, and kanamycin; aadA gene cassette conferring resistance to streptomycin and spectinomycin) were most commonly found [11].

The B-lactamase cassettes (oxa2 or blaoxa2) that confer resistance to oxacillin and ampicillin [28], were found in three isolates with amplicon size $1200 \mathrm{bp}$. The aacA4 cassette (aminoglycoside acetyl transferase) that confer resistance to gentamicin, amikacin and tobramycin, was found with amplicon size 800 bp [11, 28].

The $d f r$ cassettes ( $d f r A 1,-A 11)$ that confer resistance to trimethoprim, were also detected frequently. The sat 2 cassette confers resistance to streptothricin by encoding a streptothricin acetyltransferase [28, 29].

The diversity of gene cassettes inserted in IVRs of class 2 integrons is much lower than class 1 integrons. This reduction in diversity is probably owing to a nonsense mutation in codon 179 (ochre 179) in the integrase gene of class 2 integrons, thereby yielding a truncated, non-functional protein, the resultant integrase is therefore unable to excise existing cassettes or insert new ones [10].

Phenotypic and genotypic characterizations of integrase-positive S.aureus are shown in Table 6. Ninety percent (91 out of 101) of class 1 and $8.16 \%$ (4 out of 49) of class 2 integrons harboured at least one gene cassette. Eleven arrays were detected containing one to three cassettes, out of which eight distinct arrays were present in integrons of class 1 and three arrays in class 2 integrons. Common gene cassettes arrays were identified in S.aureus strains. In comparison with other sequences deposited in databases, the following gene cassettes were identified: gentamicin, tobramycin and kanamycin resistance genes $(\operatorname{aadB})$, gentamicin, amikacin and tobramycin resistance genes (aacA4), streptomycin and spectinomycin resistance genes (aadA1, aadA2), trimethprim resistance genes (dfrA1, dfrA11), $\beta$-lactam resistance genes (blaoxa2), chloramphenicol resistance genes (catB3, catB8 and cmlA6), streptothricin resistance genes (sat2), an orfD encoding a protein with unknown function, a putative 
Table 6 Phenotypic and genotypic characterization of isolates by different length of amplicons

\begin{tabular}{|c|c|c|c|c|c|c|c|}
\hline Strain & Source & $\begin{array}{l}\text { Size of } 5^{\prime} \mathrm{CS}-3^{\prime} \mathrm{CS} \\
\text { amplicons }\end{array}$ & $\begin{array}{l}\text { Intl } \\
\text { gene }\end{array}$ & Gene cassette array & $\begin{array}{l}\text { Integron } \\
\text { putative } \\
\text { location }^{a}\end{array}$ & Resistance phenotype & $\begin{array}{l}\text { Accession } \\
\text { number }\end{array}$ \\
\hline Sm59 & wound & $1200 \mathrm{bp}$ & I & blaoxa2 & C & CRO,LEV,TN,E,CD,LZD,RP,PG,OXA,A,S,ATH,GM,CIP,AP,SXT & KF356395 \\
\hline MMS1 & wound & $750 \mathrm{bp}$ & I & $\mathrm{aadB}$ & C & $\mathrm{CRO}, \mathrm{E}, \mathrm{CD}, \mathrm{PG}, \mathrm{A}, \mathrm{S}, \mathrm{ATHSPC}, \mathrm{GM}, \mathrm{CIP}, \mathrm{AP}, \mathrm{TE}, \mathrm{C}, \mathrm{AK}$ & KF015994 \\
\hline s61 & wound & $750 \mathrm{bp}$ & । & aadB & C & $\mathrm{CRO}, \mathrm{TN}, \mathrm{E}, \mathrm{CD}, \mathrm{PG}, \mathrm{OXA}, \mathrm{A}, \mathrm{S}, \mathrm{SPC}, \mathrm{GM}, \mathrm{CIP}, \mathrm{AP}, \mathrm{TE}, \mathrm{SXT}$ & KF030468 \\
\hline $\operatorname{sm} 54$ & blood & $1200 \mathrm{bp}$ & । & blaoxa2 & C & $\mathrm{CRO}, \mathrm{LEV}, \mathrm{TN}, \mathrm{E}, \mathrm{CD}, \mathrm{LZD}, \mathrm{RP}, \mathrm{PG}, \mathrm{OXA}, \mathrm{A}, \mathrm{S}, \mathrm{ATH}, \mathrm{GM}, \mathrm{CIP}, \mathrm{AP}, \mathrm{SXT}$ & KF305707 \\
\hline sa10 & blood & $800 \mathrm{bp}$ & I & aacA4 & C & $\mathrm{CRO}, \mathrm{LEV}, \mathrm{E}, \mathrm{CD}, \mathrm{LZD}, \mathrm{RP}, \mathrm{PG}, \mathrm{OXA}, \mathrm{A}, \mathrm{S}, \mathrm{ATH}, \mathrm{CIP}, \mathrm{AP}, \mathrm{TE}, \mathrm{SXT}$ & KF305706 \\
\hline S232 & blood & $500 \mathrm{bp}$ & I & $\begin{array}{l}\text { putative glucose } \\
\text { dehydrogenase- } \\
\text { hypothetical } \\
\text { protein }\end{array}$ & C & $\mathrm{CRO}, \mathrm{E}, \mathrm{CD}, \mathrm{PG}, \mathrm{OXA}, \mathrm{A}, \mathrm{S}, \mathrm{SPC}, \mathrm{AP}, \mathrm{TE}$ & KF411133 \\
\hline MMS2 & abscess & $750 \mathrm{bp}$ & I & aadB & C & $\mathrm{CRO}, \mathrm{E}, \mathrm{CD}, \mathrm{PG}, \mathrm{A}, \mathrm{S}, \mathrm{ATH}, \mathrm{SPC}, \mathrm{GM}, \mathrm{CIP}, \mathrm{AP}, \mathrm{TE}, \mathrm{C}, \mathrm{AK}$ & KF015995 \\
\hline s74 & blood & $1000 \mathrm{bp}$ & I & aadA2 & C & $\mathrm{CRO}, \mathrm{TN}, \mathrm{E}, \mathrm{CD}, \mathrm{PG}, \mathrm{OXA}, \mathrm{A}, \mathrm{S}, \mathrm{SPC}, \mathrm{GM}, \mathrm{CIP}, \mathrm{AP}, \mathrm{TE}, \mathrm{SXT}$ & KF411134 \\
\hline s54 & blood & $2120 \mathrm{bp}$ & I & orfD-aacA4-catBB & P & $\mathrm{CRO}, \mathrm{LEV}, \mathrm{E}, \mathrm{CD}, \mathrm{LZD}, \mathrm{PG}, \mathrm{OXA}, \mathrm{A}, \mathrm{S}, \mathrm{ATH}, \mathrm{SPC}, \mathrm{GM}, \mathrm{CIP}, \mathrm{AP}, \mathrm{TE}, \mathrm{C}, \mathrm{AK}$ & KF411135 \\
\hline s5 & wound & $1100 \mathrm{bp}$ & । & orfD-aacA4 & C & $\mathrm{CRO}, \mathrm{LEV}, \mathrm{E}, \mathrm{CD}, \mathrm{LZD}, \mathrm{PG}, \mathrm{OXA}, \mathrm{A}, \mathrm{S}, \mathrm{ATH}, \mathrm{SPC}, \mathrm{GM}, \mathrm{CIP}, \mathrm{AP}, \mathrm{TE}, \mathrm{C}, \mathrm{AK}$ & KF411137 \\
\hline$s 22$ & wound & $1000 \mathrm{bp}$ & I & aadA2 & C & $\mathrm{CRO}, \mathrm{TN}, \mathrm{E}, \mathrm{CD}, \mathrm{PG}, \mathrm{OXA}, \mathrm{A}, \mathrm{S}, \mathrm{SPC}, \mathrm{GM}, \mathrm{CIP}, \mathrm{AP}, \mathrm{TE}, \mathrm{SXT}, \mathrm{AK}$ & KF411138 \\
\hline s36 & blood & $1000 \mathrm{bp}$ & I & aadA2 & C & $\mathrm{CRO}, \mathrm{TN}, \mathrm{E}, \mathrm{CD}, \mathrm{PG}, \mathrm{OXA}, \mathrm{A}, \mathrm{S}, \mathrm{SPC}, \mathrm{GM}, \mathrm{CIP}, \mathrm{AP}, \mathrm{TE}, \mathrm{SXT}$ & KF411139 \\
\hline sm91 & blood & $1420 \mathrm{bp}$ & । & aadB-catB3 & C & $\mathrm{CRO}, \mathrm{TN}, \mathrm{E}, \mathrm{CD}, \mathrm{PG}, \mathrm{OXA}, \mathrm{A}, \mathrm{S}, \mathrm{SPC}, \mathrm{GM}, \mathrm{APC}, \mathrm{SXT}$ & KJ002505 \\
\hline sm105 & wound & $3100 \mathrm{bp}$ & । & aadB-aadA1-cmlA6 & P & CRO,LEV,E,CD,LZD,PG,OXA,A,S,ATH,SPC,GM,CIP,AP,TE,C,SXT,AK & KJ002506 \\
\hline $\operatorname{sm} 22$ & wound & $750 \mathrm{bp}$ & $\|$ & hdfrA11 & C & $\mathrm{CRO}, \mathrm{LEV}, \mathrm{TN}, \mathrm{E}, \mathrm{CD}, \mathrm{PG}, \mathrm{OXA}, \mathrm{A}, \mathrm{S}, \mathrm{SPC}, \mathrm{GM}, \mathrm{CIP}, \mathrm{AP}, \mathrm{TE}, \mathrm{SXT}$ & KF305708 \\
\hline sm97 & blood & $2500 \mathrm{bp}$ & $\|$ & dhfrA1-sat2-aadA1 & P & $\mathrm{CRO}, \mathrm{LEV}, \mathrm{TN}, \mathrm{E}, \mathrm{CD}, \mathrm{PG}, \mathrm{OXA}, \mathrm{GAT}, \mathrm{A}, \mathrm{S}, \mathrm{ATH}, \mathrm{SPC}, \mathrm{GM}, \mathrm{CIP}, \mathrm{AP}, \mathrm{TE}, \mathrm{C}, \mathrm{SXT}, \mathrm{AK}$ & KF305710 \\
\hline s92 & blood & $750 \mathrm{bp}$ & $\|$ & $\begin{array}{l}\text { hypothetical } \\
\text { protein }\end{array}$ & C & $\mathrm{CRO}, \mathrm{E}, \mathrm{CD}, \mathrm{PG}, \mathrm{OXA}, \mathrm{AS}, \mathrm{SPC}, \mathrm{AP}, \mathrm{TE}$ & KF411136 \\
\hline s105 & wound & $1230 \mathrm{bp}$ & $\|$ & dhfrA1-sat2 & C & $\mathrm{CRO}, \mathrm{LEV}, \mathrm{TN}, \mathrm{E}, \mathrm{CD}, \mathrm{LZD}, \mathrm{RP}, \mathrm{PG}, \mathrm{OXA}, \mathrm{A}, \mathrm{S}, \mathrm{ATH}, \mathrm{GM}, \mathrm{AP}, \mathrm{SXT}$ & KJ769139 \\
\hline
\end{tabular}

${ }^{a} \mathrm{c}$ chromosomal location, $P$ plasmid location, $C R O$ ceftriaxone, $L E V$ levofloxacin, $E$ erythromycin, $C D$ clindamycin, $T N$ tobramycin, $P G$ penicillin $G, L Z D$ linezolid, $O X A$ oxacillin, $A$ amoxicillin, $S$ streptomycin, ATH azithromycine, SPC spectinomycin, GM gentamycin, CIP ciprofloxacin, AP ampicillin, TE tetracycline, $C$ chloramphenicol, SXT trimethoprim-sulfamethoxazole, $A K$ amikacin

glucose dehydrogenase. Moreover, the arrays $a a d B$ and $\operatorname{aad} A 2$ in class 1 integrons were found during the entire process, indicating the most common array. Previous studies have reported aadA2, aacA4-cmlA1, dfrA17aadA5 and $d$ frA12-orfF-aadA2 genes as frequently found gene cassettes both in clinical and environmental strains [30, 31].

Common gene cassette arrangements in class 2 integrons were found in S.aureus strains (dfrA1-sat2-aadA1). It should be noted, the cassette array $d f r A 1$-sat2-aadA1 was detected most frequently in class 2 integrons [15, 30-32]. Furthermore, integron-positive isolates were resistant to different classes of antimicrobial agents but related resistance gene cassettes were not found to be harbored on the integron, implying the nonintegron sources of resistance to these antibiotics [33]. In this study, integron cassette region could not be amplified by PCR in 3 (2.9\%) and 17 (34.6\%) of the class 1 and 2 integroncontaining isolates respectively. In the cases where the cassette array could not be amplified, there is no cassettes or in the absent, significant alter-ation in the $3 \mathrm{CS}$ primer binding site or a very large size of the Integron cassette are the most likely explanations for the negative PCRs [3].

The total prevalence of integrases carried in plasmids $36 \%(50 / 139)$ was similar to that previously reported in S.aureus [34]. Nevertheless, we are aware that the prevalence obtained may be biased due to the fact that plasmid and chromosomal DNA can display the same electrophoretic mobility. The dissemination of the class 1 integrons, in many instances, has been attributed to the spread of an integron-containing transposon, $\operatorname{Tn} 21$ [35]. The distribution of $\operatorname{Tn} 7$ in clinical isolates correlates with the frequency of trimethoprim resistance [36]. Trimethoprim resistance is due to the dihydrofolate reductase enzyme encoded by the dhfr gene in $\operatorname{Tn} 7$ [29]. Class 2 integron variable regions were amplified using primers that bind to attI2 and to orfX, situated downstream of the cassette region within transposon $\operatorname{Tn} 7$ [37]. Therefore, the presence of such an integron in S.aureus may have had its origin in a transposition event. 
Antimicrobial resistance patterns revealed that $78.4 \%$ of the integrase-positive strains were multiresistant (i.e. resistant to 3 or more antibiotics).

\section{Conclusions}

This is the first report of the presence of classes 1 and 2 integrons in isolates of S.aureus in Iran. These results indicated with the spread of MDR strains, class 1 and 2 integrons carrying gene cassettes are widely disseminated among S.aureus strains in our hospital. In cases that significant relationship between the presence of integrons and antibiotic resistance were not observed, resistance could be achieved by different ways such as deficiency in cell wall enzymes or resistance under plasmid or chromosome control [38].

\section{Competing interest}

The authors declare that they have no competing interest.

\section{Authors' contributions}

MM and SS carried out the molecular genetic studies, participated in the sequence alignment and drafted the manuscript. JV carried out the sequence alignment. $\mathrm{FSH}, \mathrm{NE}, \mathrm{AM}$ participated in the sequence alignment. $\mathrm{FV}, \mathrm{AJ}$ and BR participated in the design of the study and performed the statistical analysis. EH, ASS, MR conceived of the study, and participated in its design and coordination. All authors read and approved the final manuscript.

\section{Acknowledgements}

This work was supported by Pasteur Institute of Iran. Kind cooperation of my colleagues in Department of Hepatitis and AIDS, Pasteur Institute of Iran is highly appreciated. We are very grateful to Dr. Mohammad Reza Agha Sadeghi, Dr. Seyed Mehdi Sadat for their assistance.

\section{Author details}

'Department of Mycobacteriology \& Pulmonary Research, Pasteur Institute of Iran, Tehran-Iran, No. 358, 12th Farwardin Ave, Jomhhoori St, Tehran 1316943551, Iran. ${ }^{2}$ Department of Microbiology, Karaj branch, Islamic Azad University, Karaj, Iran. ${ }^{3}$ Department of Microbiology, Pasteur Institute of Iran, Tehran, Iran. ${ }^{4}$ National Institute of Genetic Engineering and Biotechnology, Tehran, Iran. ${ }^{5}$ Biotechnology Department, Faculty of Medicine, Shahid Beheshti University of Medical Sciences, Tehran, Iran. ${ }^{6}$ Department of Anesthesiology, Iran University of Medical Sciences, Tehran, Iran. ${ }^{7}$ Department of Microbiology, Reference Health Laboratories Research Center, Ministry of Health and Medical Education, Tehran, Iran.

\section{Received: 17 February 2015 Accepted: 17 July 2015}

Published online: 31 July 2015

\section{References}

1. Hardy K, Hawkey PM, Gao F, Oppenheim BA. Methicillin resistant Staphylococcus aureus in the critically ill. Br J Anaesth. 2004;92(1):121-30.

2. Kluytmans J, Mouton JW, ljzerman EP, Vandenbroucke-Grauls CM, Maat AW, Wagenvoort JH, et al. Nasal carriage of Staphylococcus aureus as a major risk factor for wound infections after cardiac surgery. J Infect Dis. 1995;171(1):216-9.

3. Japoni-Nejad A, Rezazadeh M, Kazemian H, Fardmousavi N, van Belkum A, Ghaznavi-Rad E. Molecular characterization of the first community-acquired methicillin-resistant Staphylococcus aureus strains from Central Iran. Int J Infect Dis. 2013;17(11):e949-54.

4. Dufour P, Gillet $Y$, Bes M, Lina G, Vandenesch F, Floret $D$, et al. Community-acquired methicillin-resistant Staphylococcus aureus infections in France: emergence of a single clone that produces Panton-Valentine leukocidin. Clin Infect Dis. 2002;35(7):819-24.

5. Obayashi Y, Fujita J, Ichiyama S, Hojo S, Negayama K, Takashima C, et al. Investigation of nosocomial infection caused by arbekacin-resistant, methicillin-resistant Staphylococcus aureus. Diagn Microbiol Infect Dis. 1997;28(2):53-9.
6. van Belkum A, Kluytmans J, van Leeuwen W, Bax R, Quint W, Peters E, et al. Multicenter evaluation of arbitrarily primed PCR for typing of Staphylococcus aureus strains. J Clin Microbiol. 1995;33(6):1537-47.

7. Gu B, Pan S, Wang T, Zhao W, Mei Y, Huang P, et al. Novel cassette arrays of integrons in clinical strains of Enterobacteriaceae in China. Int J Antimicrob Agents. 2008;32(6):529-33.

8. Yang B, Zheng J, Brown EW, Zhao S, Meng J. Characterisation of antimicrobial resistance-associated integrons and mismatch repair gene mutations in Salmonella serotypes. Int I Antimicrob Agents. 2009;33(2):120-4.

9. Tamang MD, Oh JY, Seol SY, Kang HY, Lee JC, Lee YC, et al. Emergence of multidrug-resistant Salmonella enterica serovar Typhi associated with a class 1 integron carrying the dfrA7 gene cassette in Nepal. Int J Antimicrob Agents. 2007;30(4):330-5.

10. Mazel D. Integrons: agents of bacterial evolution. Nat Rev Microbiol. 2006; $4(8): 608-20$

11. Japoni-Nejad A, Farshad S, van Belkum A, Ghaznavi-Rad E. Novel cassette array in a class 1 integron in clinical isolates of Acinetobacter baumannii from central Iran. Int J Med Microbiol. 2013;303(8):645-50

12. Kloos WE. Staphylococcus and micrococcus. Manual of clinical microbiology, 1995. p. 282-298.

13. Wikler MA. Performance Standards for Antimicrobial Susceptibility Testing: Nineteenth Informational Supplement. 2009: Clinical and Laboratory Standards Institute.

14. Sambrook J, Fritsch EF, Maniatis T. Molecular Cloning. Vol. 2. New York: Cold spring harbor laboratory press; 1989.

15. Moura A, Henriques I, Ribeiro R, Correia A. Prevalence and characterization of integrons from bacteria isolated from a slaughterhouse wastewater treatment plant. J Antimicrob Chemother. 2007;60(6):1243-50.

16. Su J, Shi L, Yang L, Xiao Z, Li X, Yamasaki S. Analysis of integrons in clinical isolates of Escherichia coli in China during the last six years. FEMS Microbiol Lett. 2006:254(1):75-80.

17. Japoni-Nejad A, Rezazadeh M, Kazemian H, Fardmousavi N, Ghaznavi-Rad E. Molecular characterization of clindamycin constitutive and inducible Resistance Staphylococcus aureus strains' isolated from nose of carriers. ISMJ. 2014:17(1):33-41.

18. Mazel D, Davies J. Antibiotic resistance in microbes. Cell Mol Life Sci. 1999:56(9-10):742-54.

19. Ploy M-C, Lambert T, Couty JP, Denis F. Integrons: an antibiotic resistance gene capture and expression system. Clin Chem Lab Med. 2000;38(6):483-7.

20. Normark BH, Normark S. Evolution and spread of antibiotic resistance. J Intern Med. 2002;252(2):91-106.

21. Ochman H, Lawrence JG, Groisman EA. Lateral gene transfer and the nature of bacterial innovation. Nature. 2000;405(6784):299-304.

22. Xu Z, Shi L, Alam MJ, Li L, Yamasaki S. Integron-bearing methicillin-resistant coagulase-negative staphylococci in South China, 2001-2004. FEMS Microbiol Lett. 2008:278(2):223-30.

23. Stokes H, Hall RM. A novel family of potentially mobile DNA elements encoding site-specific gene-integration functions: integrons. Mol Microbiol. 1989;3(12):1669-83.

24. Xu Z, Li L, Shi L, Shirtliff ME. Class 1 integron in staphylococci. Mol Biol Rep. 2011;38(8):5261-79.

25. Ren C, Zhao Y, Shen Y. Analysis of the effect of integrons on drug-resistant Staphylococcus aureus by multiplex PCR detection. Mol Med Rep. 2013;7(3):719-24

26. Phongpaichit S, Wuttananupan K, Samasanti W. Class 1 integrons and multidrug resistance among Escherichia coli isolates from human stools. 2008.

27. Kargar M, Mohammadalipour Z, Doosti A, Lorzadeh S, Japoni-Nejad A. High prevalence of class 1 to 3 integrons among multidrug-resistant diarrheagenic Escherichia coli in Southwest of Iran. Osong Public Health Res Perspect. 2014;5(4):193-8.

28. Recchia GD, Hall RM. Gene cassettes: a new class of mobile element. Microbiology. 1995;141(12):3015-27.

29. Xu Z, Li L, Shirtliff ME, Peters BM, Li B, Peng Y, et al. Resistance class 1 integron in clinical methicillin-resistant Staphylococcus aureus strains in southern China, 2001-2006. Clin Microbiol Infect. 2011;17(5):714-8.

30. van Essen-Zandbergen A, Smith H, Veldman K. Mevius D. Occurrence and characteristics of class 1,2 and 3 integrons in Escherichia coli, Salmonella and Campylobacter spp. in the Netherlands. J Antimicrob Chemother. 2007;59(4):746-50 
31. Cocchi S, Grasselli E, Gutacker M, Benagli C, Convert M, Piffaretti JC. Distribution and characterization of integrons in Escherichia coli strains of animal and human origin. FEMS Immunol Med Microbiol. 2007:50(1):126-32.

32. Kang HY, Jeong YS, Oh JY, Tae SH, Choi CH, Moon DC, et al. Characterization of antimicrobial resistance and class 1 integrons found in Escherichia coli isolates from humans and animals in Korea. J Antimicrob Chemother. 2005;55(5):639-44.

33. Chang Y-C, Shih DY, Wang JY, Yang SS. Molecular characterization of class 1 integrons and antimicrobial resistance in Aeromonas strains from foodborne outbreak-suspect samples and environmental sources in Taiwan. Diagn Microbiol Infect Dis. 2007;59(2):191-7.

34. Tennstedt T, Szczepanowski R, Braun S, Pühler A, Schlüter A. Occurrence of integron-associated resistance gene cassettes located on antibiotic resistance plasmids isolated from a wastewater treatment plant. FEMS Microbiol Ecol. 2003;45(3):239-52.

35. Bass L, Liebert CA, Lee MD, Summers AO, White DG, Thayer SG, et al. Incidence and characterization of integrons, genetic elements mediating multiple-drug resistance, in avianEscherichia coli. Antimicrob Agents Chemother. 1999;43(12):2925-9.

36. Chang L-L, Chang JC, Chang CY, Chang SF, Wu WJ. Genetic localization of the type I trimethoprim resistance gene and its dissemination in urinary tract isolates in Taiwan. Kaohsiung J Med Sci. 1997;13(9):525-33.

37. White PA, Mclver CJ, Rawlinson WD. Integrons and gene cassettes in the Enterobacteriaceae. Antimicrob Agents Chemother. 2001;45(9):2658-61.

38. Abbo A, Navon-Venezia S, Hammer-Muntz O, Krichali T, Siegman-lgra Y, Carmeli Y. Multidrug-resistant Acinetobacter baumannii. Emerg Infect Dis. 2005:11(1):22-9.

\section{Submit your next manuscript to BioMed Central and take full advantage of:}

- Convenient online submission

- Thorough peer review

- No space constraints or color figure charges

- Immediate publication on acceptance

- Inclusion in PubMed, CAS, Scopus and Google Scholar

- Research which is freely available for redistribution 